\title{
A New Capability Maturity Model For Reuse Based Software Development process
}

\author{
Jasmine K.S, Member, IACSIT, Dr. R. Vasantha
}

\begin{abstract}
For any industrial organizations, improving the business performance often means the improvement in their software development performance. The growing popularity of developing the software using reusable components could dramatically reduce development effort, cost and accelerate delivery. To achieve this goal it is necessary to define a systematic reuse strategy as part of organization daily activities. Often, gains in product quality, productivity, cost reduction, cycle time reduction, and even customer satisfaction are offered to corporate decision-makers to justify investment in adoption of the CMMI. This paper provides an approach and mechanisms for making CMMI investment decisions based on impact on ROI by proposing a new process based capability maturity model for reuse based development process.
\end{abstract}

Index Terms - capability maturity model, CMMI, process maturity framework, software process improvement, process capability, process performance, maturity level, software reuse.

\section{INTRODUCTION}

The decision to adopt the CMMI within an organization is multi-faceted. The CMMI framework must be compared to other improvement options, such as ISO 9001-2000, the SW-CMMÒ, clean room methodologies, inspections, or software reuse. If the decision to adopt the CMMI is made, several options then present themselves.

There are three most important variables affecting Return on Investment for a CMMI implementation effort. They are:

- Performance or Quality Goals

- Value Domains

- Contract types

Again there are three value domains that may be affected or improved through successful CMMI adoption:

- $\quad$ Product life cycle

- Marketing value

- Intrinsic value to the organization

Product life cycle value stems from increases in productivity and product quality, reduced costs, and reduced time-to-market.

Jasmine K.S is with RVCE, Visveswaraya Technological University, Asst.Professor, Dept of MCA, Bangalore, India (phone: +919916101571; e-mail: jasminesadeep@yahoo.co.in).

Dr. R. Vasantha is with RVCE, Visveswaraya Technological University, Prof, Dept of ISE, Bangalore, India (e-mail: vasanthaprak@yahoo.com).

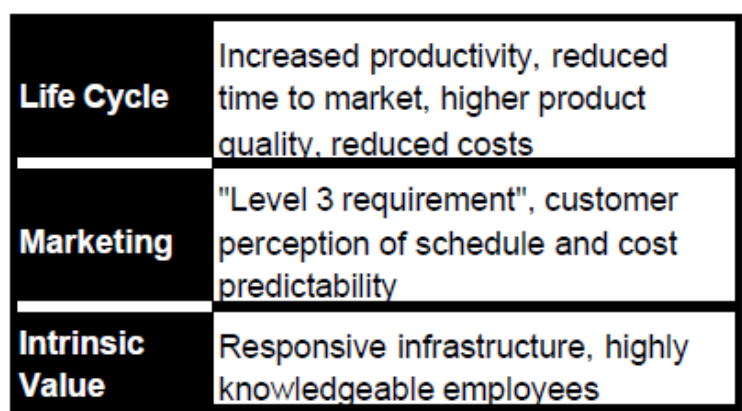

Fig1.Organization's value perception related to CMMI implementation

Marketing value is based on the perception of the potential customer. If CMMI compliance is a condition of contract award, or if the acquiring organization is sufficiently aware of the value of CMMI compliance, that compliance would presumably have a direct impact on contract award.

Intrinsic value to the organization is defined as the knowledge or skills of its members, and the ability of its infrastructure to respond to the needs of the engineering organization.

Since the product life cycle value has been the dominant focus of ROI calculations over the years, the proposed CMMI for reuse focuses on the control and monitor the reuse process and integrate reuse into software life cycle compared to other value domains.

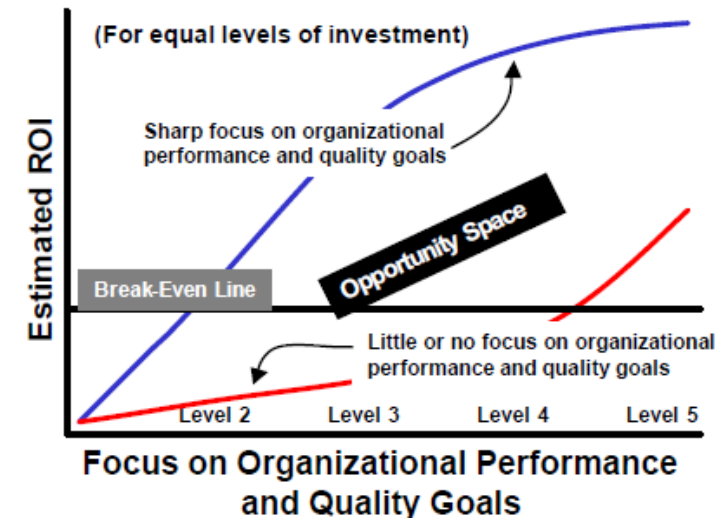

Fig2.ROI affected by goal setting

A heuristic view of the potentially radical increase in ROI is provided in Figure 2. The curves are estimated boundary conditions for organizations that invest roughly equal amounts on their CMMI programs. Thedifference in ROI is the attention paid on understanding the organization's business environment, and then on focusing the CMMI effort on helping the organization to achieve important management 
and engineering goals through its CMMI program.

The following figure depicts the decision process for adoption of CMMI

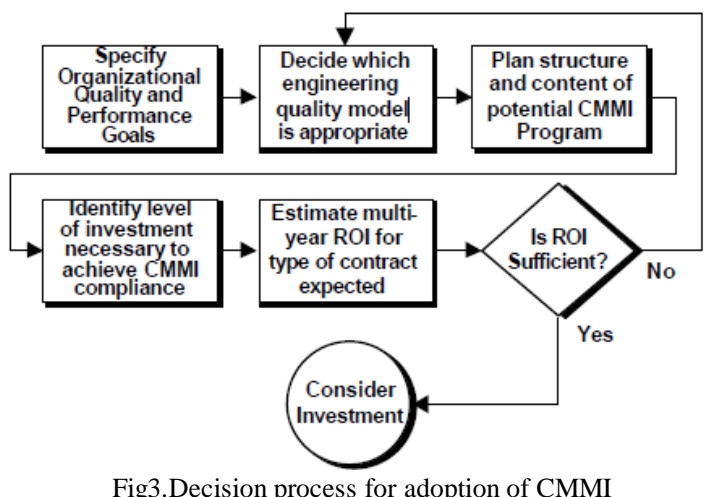

\section{A. Motivation For Reuse}

Motivation for developing the Reuse Maturity Model comes from observing the enormous impact the Software Engineering Institute's software Capability Maturity Model has had. The SEI has focused attention on process issues in a most remarkable way by examining characteristic engineering practices and providing a means to classify an organization into one of five maturity levels [7]-[8],[44]. Moreover, the SEI has established the principle in people's minds that the quality of a software product is dictated by the quality of the processes used to develop that product. Furthermore, the SEI has convinced executive managers that process improvement must come a step at a time, by laying a foundation for process improvement on which other improvement activities can build. Through the proposed Reuse Maturity Model, we hope that achieving reuse requires a comprehensive approach.

From the survey conducted in various software companies, a numerous obstacles are identified that must be overcome in order to achieve high levels of reuse, are listed below:

Cultural: Incentives and management backing must be put in place and ("Not Invented Here") syndrome must be eliminated.

Institutional: A corporate-wide forum is needed to identify product development cycle where reuse concerns can always be raised and resolved.

Financial: The costs and benefits must be understood for a product life cycle based on a "Design for Reuse" philosophy. Reusable work-products must be viewed as capital assets.

Technical: Proper mechanisms are needed to ensure that guidelines, techniques, and standards for making things reusable are developed and followed.

Legal: Negotiations must be undertaken to determine how to retain rights to components developed under customer contract and recover costs in a reuse context. Mechanisms will be needed for payment and collection of royalties for use and reuse in the commercial arena.

Out of the hundred industrial organizations considered, we could see many Level 1 Reuse organizations, only a handful of companies at the intermediate levels, and only hypothesize what a Level 5 Reuse company would look like. We expect some significant revisions are needed to the model. An additional step which augments the reuse maturity questionnaire and by organizing subsets of the questions to address each level of reuse maturity separately is required to objectively measure the Progress toward reuse process improvement.

\section{B. Steps to Achieve Effective Reuse}

To provide organizations with detailed guidance on how to achieve effective reuse, the Reuse-driven Software Processes (RSP) methodology was also developed at SPC in the early 1990's. All RSP processes consist of two distinct lifecycle activities of domain engineering and application engineering. The conceptual basis of any RSP process is the formalization of commonalities and variabilities that characterize a set of similar products to represent a product family and an associated process for deriving instance products to meet diverse and changing customer needs.

Other authors have proposed different models to structure the breadth of reuse involvement provided by an organization. Among them one was proposed by [31], that proposed by the Software productivity Consortium and that used in the UE project REBOOT (Reuse Based on Object oriented Techniques).

The model proposed by Koltun and Hudson, five maturity levels are defined for reuse [31]:

1- Initial Chaotic

2- Monitored

3- Co-coordinated

4- Planned

5- Ingrained

The criteria that permit the evaluation of the level of each organization in the model are:

Motivation, Planning for reuse, Breadth of reuse involvement, Responsibility for making reuse happen, process by which reuse is leveraged, reuse inventory, classification activity, Technology support, metrics and legal considerations.

The model suggested by Llorens Morillo et. al, is based on the monitoring of three different factors [48]

- Repository structure

- Software development architecture

- Administrative management

Each factor encompasses a certain part of the reuse environment, covering the following areas of control.

Repository structure deals with information representation of the available information in techniques to obtain wherever necessary, and management of authorizing, rejecting and modification of existing components and automated announcement of incorporation or modification of components [47].

Software Development architecture includes developing the architecture according to its orientation towards reuse, type of reuse systematically achieved by the organization and component testing.

Under administrative management, three aspects are covered [8].Reuse support towards human resources

- Incentives and planning towards reuse

- Reuse level of previous projects, applied to the strengthening of the level of improvement

The complete infrastructure graph recommended is shown in 
following figure [49].

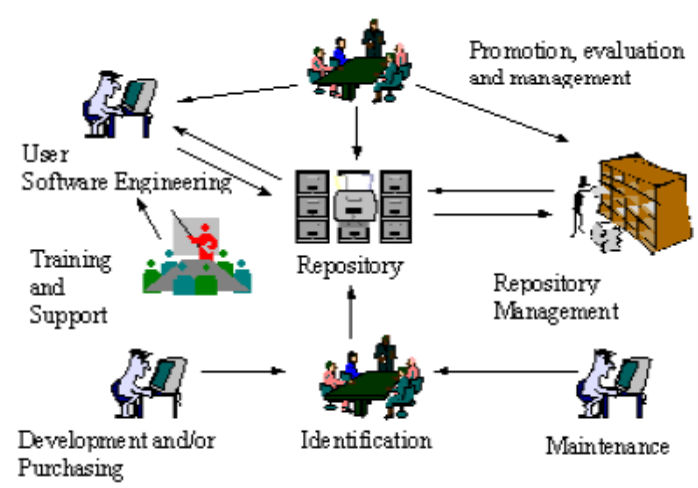

Fig4. Reuse Infrastructure

According to Grady, a reuse-driven process is a framework for performing domain specific engineering which helps to optimize the software practices to build products of a particular type, resulting in improved productivity and product quality [29]. This focusing and standardization of effort is the key to systematic reuse, leading ultimately to a manufacturing discipline.

As with any process, the CMM and RCM process improvement factors can motivate improvements in a reuse-driven process. In this, some of the corresponding RCM factors ought to be addressed in attaining CMM levels 2 and 3 . The 17 process definition factors in the RCM concern differences in the types of reuse based process that an organization may adopt [29]. The RCM, in its implementation model, defines four types of reuse based process: opportunistic, integrated, leveraged, and anticipating. These types, ordered by increasing cost-risk and benefit, provided a categorization for the diversity of approaches already envisioned by the RSP methodology as a family of processes. These process definition factors do not fit into the proper scope of the CMM because they involve a choice among equally valid alternative process conceptions; no one approach is best for everyone.

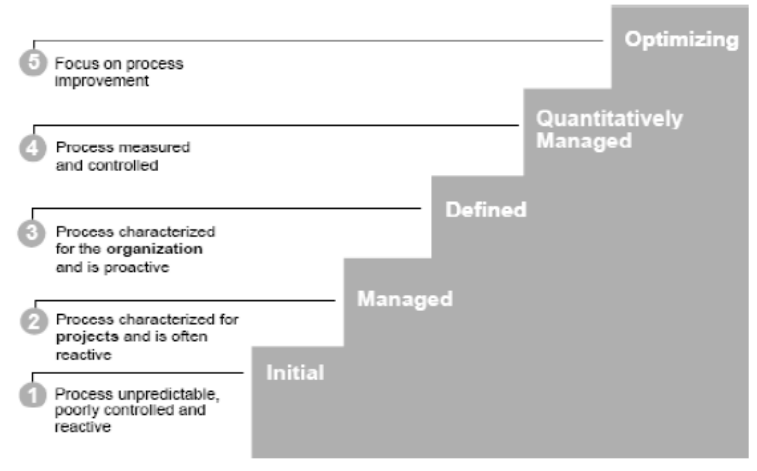

Fig5. Traditional CMM Levels

\section{IMPLEMENTATION}

\section{A. Proposed CMM levels by the author for reuse}

Although process maturity is extremely important in delivering high quality software, there is no standardized maturity model adopted for reuse based software development process. Some organizations which are primarily involved in reuse based software development are following some versions of reuse maturity models. After an extensive literature review [3],[36],[25],[42] and from the study on reuse projects, we have identified some factors related to software reuse similar to the study by [19],[38],[48] that were considered as a basis for this maturity model specification, in order to guide the organizations in the reuse evaluation and/or adoption.

RCMM is a maturity model with focus on reuse and describes which are basic in order to ensure a well planned and controlled reuse oriented software development. In RCMM, there are 5 levels inspired by SEI's Capability Maturity Model. Each level represents a stage in the evolution to a mature reuse process. A set of maturity goals for each level and the activities, task and responsibilities, needed to support are shown in the figure6.

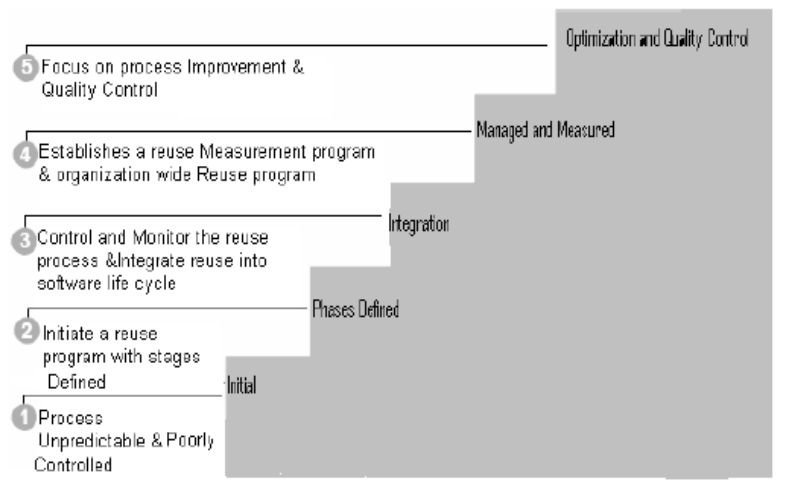

Fig6. Proposed CMM Levels for Reuse

The RCMM model suggested here can be used as s a basis for estimating the level of software reuse practice within an organization. As future work, Maturity Model aims at identifying the strengths of an organization with respect to software reuse and the opportunities for improvements can be adopted. Correct implementation of software reuse and the benefits for an organization adopting reuse in their processes can be evaluated only based on quantitative data. Therefore appropriate reuse business and engineering metrics are recommended to be used within the maturity model to measure the achievement of the respective objectives, the efficiency of the applied practices and the quality of the results obtained. To evaluate the suggested model, it has to be put in the industrial environment and there is a need to get more feedbacks from experts to evaluate the current reuse practice stage and plan the next activities to implement the reuse program.

\section{CONCLUSIONS \& FUTURE STUDY}

Good management can make a difference for success in the case of reuse based software development. Proper monitoring and control of the progress towards the business goals and the performance compliance needs an effective management program. However the nature of the reuse business changes the character and extent of the issues. By suitably applying some modifications to the traditional management techniques by keeping in mind the reuse business goals and proper planning 
will lead to success in reuse business.

By gathering issues associated with people, process and product measurements and by estimating and validating them ensures that proper usage of resources will follow the right process and right product.

\section{ACKNOWLEDGMENT}

The author would like to thank the members of both the management and technical committees of various industry projects who worked together and contributed with numerous useful suggestions towards the successful completion of this research.

\section{REFERENCES}

[1] Abts, C., Boehm, B. \& Bailey Clark, B., (2000a). COCOTS: a COTS software integration cost model, Proceedings ESCOM-SCOPE 2000 Conference, April.

[2] Abts, C.; Boehm, B \& Bailey Clark, B. (2000b). Empirical Observations on COTS Software Integration Effort Based on the Initial COCOTS Calibration Database, ICSE 2000 COTS Workshop - mip.sdu.dk

[3] Almeida, E. S., Alvaro, A., Lucr'edio, D., Garcia, V. C., \& Meira, S. R. L. (2004). Rise project:Towards a robust framework for software reuse. IEEE International Conference on Information Reuse and Integration (IRI), pp. 48-53, Las Vegas, USA.IEEE/CMS

[4] Balda, D.M. \& Gustafson, D.A. (1990). Cost-estimation models for the reuse and prototype software development, ACM SIGSOFT, pp. 42-50, July

[5] Basili, V.R.; Briand, L. C. \& Thomas, W. M. (1994). Domain Analysis for the Reuse of Software Development Experiences, Proceedings of the 19th Annual Software Engineering Workshop, NASA/Goddard Space Flight Center, November.

[6] Balda, D. and Gustafson, D.(1990). Cost estimation Models for the Reuse and Prototype Software Development Life-cycles.ACM SIGSOFT Software Engineering Notes Vol.15, No. 3, Pages 42-50, July.

[7] Bass, L.; Clements \& Cohen. S. et al. (1997). Product Line Practice Workshop Report,Technical Report CMU/SEI-97-TR-003, Software Engineering Institute, June.

[8] Baumert, John; Mc Whinney \&Mark.(1992).Software Measures and the Capability Maturity Model., Software Engineering Institute,CMU/SEI-92-TR-25, Pittsburgh, PA USA,September.

[9] Bosch, J. \& Molin, P. (1997). Software Architecture Design: Evaluation and Transformation,Research Report 14/97, University of Karlskrona/Ronneby, August.

[10] Bosch, J. (1998a). Object Acquaintance Selection and Binding, Theory and Practice of ObjectSystems, February.

[11] Bosch, J. (1998b). Product-Line Architectures in Industry: A Case Study, Proceedings of the21st International Conference on Software Engineering, November.

[12] Bosch, J. (1999). Evolution and Composition of Reusable Assets in Product-Line Architectures: A Case Study. www:http://www.ide.hk-r.se/ bosch

[13] Boehm, B.M \& Papaccio, P.N.(1998).Understanding and controlling software costs, IEEE transactions on software engineering, 14(10), $1462-77$

[14] Boehm, B., Clark, B.et al.(1995) Cost Models for Future Software Lifecycle Processes:COCOMO 2.0, Annals of Software Engineering.

[15] Boehm, B.W (1981). Software Engineering Economics, Englewood Cliffs, NJ Prentice Hall.

[16] Boehm, B. \& Abts, C.et al. (2000).Software Cost Estimation with COCOMO II, Prentice Hall, NJ,June.

[17] Barnes, B.H. \& Bollinger, T.B. (1991), Making reuse cost-effective, IEEE software, Vol. 8,No.1,pp. 13-24, January.

[18] Banker, R. D. \& Kauffman, R. J. et.al(1993).Evaluation of Software Reuse, IEEE Transactions on Software Engineering, Vol. 19, No. 4, pp. 379-389, April.

[19] Brito, K. S., Alvaro, A., Lucr'edio, D., Almeida, E. S., and Meira, S. R. L. (2006). Software reuse: A brief overview of the brazilian industry's case. 5th ACM-IEEE International Symposium on Empirical Software Engineering (ISESE), Short Paper, Rio de Janeiro,Brazil. ACM Press.

[20] Buschmann, F; Jäkel,C \& Meunier,R.et al.(1996).Pattern-Oriented Software Architecture- A System of Patterns, John Wiley \& Sons.
[21] Chidamber, S. R. \& Kemerer, C. F.(1994). A Metrics Suite for Object Oriented Design, IEEE Transactions on Software Engineering, vol. 20, pp. 476-493.

[22] Dikel, D.; Kane, D. \& Ornburn, S. et al (1997). Applying Software Product-Line Architecture,'IEEE Computer, pp. 49-55, August.

[23] Frakes, W. \& Terry, C. (1994).Reuse Level Metrics, Proceedings of the 3rd International Conference on Software Reuse: Advances in Software Reusability, IEEE.

[24] Davis, T. (1993). The reuse capability model: A basis for improving an organization's reuse capability. Proceedings of 2nd ACM/IEEE International Workshop on SoftwareReusability, pp. 126-133. IEEE Computer Society Press / ACM Press.

[25] Frakes, W. B. and Fox, C. J. (1995). Sixteen questions about software reuse. Communications of the ACM, 38(6):75-87. ACM Press. New York, NY, USA.Frakes, W. \& Terry, C. (1996).Software Reuse: Metrics and Models, ACM Computing Surveys,Vol. 28, No. 2, June.

[26] Favaro, J. A. (1996).Comparison of Approaches to Reuse Investment Analysis. Proceedings of the Fourth International Conference on Software Reuse, IEEE Computer Society Press,pp.136-145, Los Alamitos, CA.

[27] Geels. (2005). Technological Transitions and System Innovations: A co-evolutionary and sociotechnical analysis, Edward Elgar, Cheltenham

[28] Guo, J. \& Luqui.(2000).A Survey of Software

Reuse Repositories, 7th IEEE International Conference and Workshop on the Engineering of Computer Based Systems, April.

[29] Grady,Campbell.(1997) Tailoring Reuse-Driven Processes In A Process Improvement Context, ERW-97 Position Paper, October

[30] Graves, S. B.(1989).The Time-Cost Tradeoff in Research and Development: A Review,Engineering Costs and Production Economics, 16, pp. 1-9, Elsevier Science Publishers.

[31] Griss, M. L., Favaro, \& P. Walton.(1993). Managerial and Organizational Issues - Starting and Running a Software Reuse Program, Software, Shaefer, March.

[32] Harris, K.(1992).Using an Economic Model to Tune Reuse Strategies", Proceedings of the $5^{\text {th }}$ Annual Workshop on Software Reuse.

[33] Henry, E. \& Faller,B. (1995).Large-Scale Industrial Reuse to Reduce Cost end Cycle Time, IEEE Software, Vol. 12, No. 5, September.

[34] Transition Parameters For Successful Reuse Business 35 Van Jacobson; Martin Griss \& Patrik Jonsson. (2000).Software ReuseArchitecture, Process and Organization for Business Success, ACM Press.

[35] Jacobson, I.; Griss, M. \& Jönsson, P. (1997). Software Reuse Architecture, Process and Organization forBusiness Success, Addison-Wesley.

[36] Koltun, P. \& Hudson, A., (1991). A reuse maturity model. 4th Annual Workshop on Software Reuse, Hemdon, Virginia: Center for Innovative Technology.

[37] Laraman, C. \& Basili, V.R., (2003). Iterative and Incremental Development: A Brief History.IEEE Computer, 2003. 36(6): p. 47-56.

[38] Larry McCarthy.(2002). Motorola CMMI Working Group,CMMISM Transition in a Commercial Environment, 2nd CMMISM Technology Conference and User Group,Hyatt Regency Denver Technical Center, November, Denver, Colorado.

[39] Lim, W. (1994). Effects of Reuse on Quality, Productivity, and Economics, IEEE Software, Vol. 11, No. 5, September.

[40] Malan, R. \&Wentzel, K. (1993).Economics of software reuse revisited, Proc. 3rd Irvine Software Symposium, University of California, Irvine, 30 April, pp.109-21.

[41] Poulin, J.S., (2006). The business case for software reuse: Reuse metrics, economic models, organizational issues, and case studies. Tutorial notes.

[42] Rine, D. C. \& Sonnemann, R. M. (1998). Investments in reusable software. a study of software reuse investment success factors. The Journal of Systems and Software, 41:17-32.

[43] Rushby Craig\& Bruce Allgood (2001).CMMI: A Comprehensive Overview.CMMI User Group, Computer Resources Support Improvement Program, Hill AFB, UT, November.

[44] Suz Garcia. (2003),On the TRIAL to CMMI® : A Framework for Effective Transition Management Practices, SEI Technology Transition Practices, Carnegie Mellon University, Pittsburgh, PA 15213-3890.

[45] WWW.sei.cmu.edu/publications/documents/02.re ports/02tr007.html

[46] SEI/CMU. (2003). INDIA 2003 presentation on TTP website www.sei.cmu.edu/ttp

[47] Topaloglu,Y.; Dikenelli,O \& Sengonca,H. (1996),Afour Dimensional reuse Maturity Model, Symposium on Computer and Information Sciences. ISCIS-XI, Antalya, Turkey. November. 
[48] Llorens Morillo et al.(2006) Incremental Software Reuse, Lecture Notes in Computer Science, 386-389, Springer Berlin / Heidelberg publishers.

[49] Prieto-D'raz, R. \& Frakes W.b.,eds(1993).Advances in software reuse: Selected papers from the second International Workshop on software reusability,Los Alamitos,California,March,IEEE Computer Society Press.

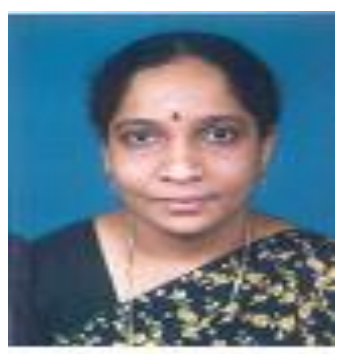

Jasmine K.S born in the Ernakulam District of Kerala state on October $14^{\text {th }}$ in the year 1971. She received BSc degree in Mathematics from Mahatma Gandhi University, Kerala in 1991, MSc degree in computer science from Kerala University, Kerala in 1994 and M.Phil degree in computer science from Bharathidasan University, Tamilnadu in 2005. She is currently doing her $\mathrm{PhD}$ in computer science in Mother Teresa University, Kodaikanal, Tamilnadu. She is working as Assistant professor in the Department of MCA, R.V.College of Engineering, Bangalore. Since from 1995, she is working as a lecturer in the field of computer science. During 98-99, She held a visiting faculty position at Visveswarapura College of science, Bangalore. She has authored 27 research papers in the national and international level journals and conferences. She has also written a book chapter for the book titled "Engineering the Computer Science and IT", ISBN 978-953-7619-32-9, November 2009 by In-Tech, worlds first advanced technologies open access platform, Vienna, Austria. Her research interests include Software reuse, Software performance, Software testing, data mining and experimental software engineering. Ms. Jasmine is the member of Indian society for technical education (ISTE), Computer society of India (CSI), International Society for Computer Applications (ISCA), International Association of Engineers (IAENG) and International Association of Computer Science and Information Technology (IACSIT).

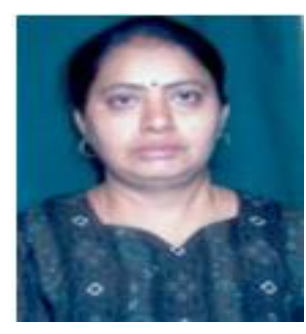

Dr.R.Vasantha received BSc degree, majored in Physics, Chemistry and Mathematics from University of Mysore, India in 1976, MSc degree in Mathematics from Manasa Gangotri, University of Mysore, India in 1978 and $\mathrm{PhD}$ from Indian Institute of Science, Bangalore, India in 1985. She is a professor in the Department of Information science and Engineering, R.V.College of Engineering, Bangalore. She got more than 25 years of research experience. During Oct.1991-Oct.1994, she worked as a Scientist in National Aeronautical Laboratory, Bangalore, India, on Turbulence modeling of aerofoil.Sept1988-Sept.1991: Worked as Research Associate in the Dept. of Mechanical Engineering, University of New South Wales \& University of Sydney, Sydney, Australia on turbulence modeling. Oct.1987-Sept.1988: Worked as a Senior Research Associate in the School of Mathematics, University of East Anglia, Norwich, England, on the initiation of detonation waves, Oct.1986-Oct.1987: Worked as a Senior Visiting Fellow in the School of Mathematics, University of East Anglia, Norwich, England. Aug.1985-Aug.1986: Worked as Research Associate in Dept. of Aerospace Engineering, IISc, Bangalore, India. She also has many years of teaching experience. During 1978-1980, she worked as a Lecturer, 1994-2002: Worked as Associate Professor of Mathematics, 2002-2006: Worked as Professor \& HOD of Mathematics in an Engineering College in India. Her research interests are in the field of computational fluid mechanics. She is the author and coauthor of several publications appearing in international journals, books, and conference proceedings in the fields of Applied Mathematics and Computational fluid mechanics. Dr. Vasantha is a Gold medal contender for $\mathrm{PhD}$ dissertation. And also she Won Scholarship from B.Sc. till the end of Ph.D. 